\title{
Multiscale characterization of nanostructured Al-Si-Zr alloys obtained by rapid solidification method
}

\author{
Mariusz Andrzejczuk • Małgorzata Lewandowska • \\ Jerzy Latuch • Krzysztof Jan Kurzydłowski
}

Received: 30 July 2010/Accepted: 18 March 2011/Published online: 30 March 2011

(c) The Author(s) 2011. This article is published with open access at Springerlink.com

\begin{abstract}
Properties of engineering metallic alloys (e.g., fracture toughness, corrosion resistance) are often limited by the presence of primary intermetallic particles which form during conventional solidification. Rapid solidification brings about much more homogenous amorphous and/ or nanocrystalline structure with reduced density of primary particles. Rapidly solidified thin ribbons obtained by melt spinning are usually considered as intrinsically homogenous. However, due to different cooling conditions at the wheel surface and on the side exposed to the ambient environment, structure of such ribbons may vary significantly across its thickness. The materials studied in this study were $30-40 \mu \mathrm{m}$ thickness ribbons of nanocrystalline hyper- and hypo-eutectic $\mathrm{Al}-\mathrm{Si}-\mathrm{Zr}$ alloys produced by melt-spinning method. Transmission electron microscopy and high resolution scanning transmission electron microscopy were used to characterize the structure homogeneity across the ribbons. Thin foils for transmission observations were prepared by focused ion beam system. Microstructural observations confirmed nanocrystalline character of $\mathrm{Al}-\mathrm{Si}-\mathrm{Zr}$ alloys. However, these observations revealed inhomogeneity of the structure across the ribbon width.
\end{abstract}

This article has been presented as a part of the European Materials Research Society E-MRS 2010 Spring Meeting Symposium Q

'Quantitative Electron Microscopy for Research and Industry'.

M. Andrzejczuk $(\bowtie) \cdot$ M. Lewandowska · J. Latuch ·

K. J. Kurzydłowski

Faculty of Materials Science and Engineering, Warsaw

University of Technology, Wołoska 141,

02-507 Warszawa, Poland

e-mail: mandrzejczuk@inmat.pw.edu.pl

\section{Introduction}

Al-Si alloys have low weight, high strength, relatively low coefficient of thermal expansion and high wear resistance, which make them suitable for a number of applications [1]. Unfortunately, the conventional way of solidification of these alloys leads to coarse microstructure with relatively large brittle Si particles, which deteriorate the mechanical properties, in particular reduce plasticity and fracture toughness [2].

Rapid solidification (RS) is in general one of the efficient ways of microstructure homogenizing and refinement of metals and alloys [3]. It can be implemented in a number of techniques, including melt spinning which is one of the most popular for thin flat elements [4]. The RS route was used to obtain highly uniform nanostructures in a number of alloys, which brought about excellent mechanical and anti-corrosion properties [5]. In the case of $\mathrm{Al}-\mathrm{Si}$ alloys, these properties depend also on the content of transition and rare earth elements [6, 7]. In this context, it was reported that $\mathrm{Zr}$ addition refines grain size and results in enhanced mechanical properties due to the formation of intermetallic particles [8].

Microstructure features of RS alloys are routinely studied/ controlled via Transmission Electron Microscopy, TEM. In the case of RS ribbons, such observations are usually performed using thin foils cut parallel to the ribbon surface, with little attention paid to the possible variation of the micro/ nano-structure as a function of the distance from the surface $[2,9]$. Such an assumption is intuitively backed-up by the small thickness of the RS ribbons. On the other hand, there is a clear difference in cooling rates at wheel and air side, which may result in a significant difference near to these two surfaces of the ribbons. In this study, an attempt has been made to investigate the relevance of such differences using as an example hypo and hypereutectic $\mathrm{Al}-\mathrm{Si}-\mathrm{Zr}$ alloys. The 
motivation for the investigation was possible consequences of the structure differentiation for further processing of ribbons, in particular for consolidation in bulk nanocrystalline samples.

\section{Experimental details}

Two ternary $\mathrm{Al}-\mathrm{Si}-\mathrm{Zr}$ alloys with $0.5 \%$ of $\mathrm{Zr}$ and different content of $\mathrm{Si}\left(\mathrm{Al}_{90.5} \mathrm{Si}_{9} \mathrm{Zr}_{0.5}\right.$ and $\left.\mathrm{Al}_{84.5} \mathrm{Si}_{15} \mathrm{Zr}_{0.5}\right)$ were prepared by arc melting of pure elements in argon atmosphere. The melt was ejected onto copper wheel rotating with a speed of $50 \mathrm{~ms}^{-1}$ that provides fast quenching. The obtained ribbons were $2-3 \mathrm{~mm}$ wide and $30-40 \mu \mathrm{m}$ thick.

The microstructure of the alloys was characterized by TEM JEOL 1200 with accelerating voltage $120 \mathrm{kV}$. The nanostructure analyses were performed with high resolution scanning transmission electron microscopy (HR-STEM) Hitachi HD-2700 equipped with energy-dispersive X-ray analysis (EDX) and operating at $200 \mathrm{kV}$. This microscope has also high angle annular dark field (HAADF) detector, which worked with collecting angle from 70 to $370 \mathrm{mrad}$ that enable obtaining images with composition contrast.

Specimens for HR-STEM and TEM observations were prepared in the form of thin foils with the thickness less than $100 \mathrm{~nm}$ by a single focused ion beam (FIB) system (Hitachi FB-2100) by lift-out preparation technique. These specimens were perpendicular to the ribbons surface to allow for through-thickness characterization of the ribbons. The microstructure of ribbons at wheel and air surfaces was observed in FIB (secondary electron mode) thanks to strong crystallographic contrast. These observations were carried out on as-melt-spun surfaces (without chemical etching).

The obtained microstructures were quantitatively described in terms of grain size and shape. The grain size was determined using the equivalent diameter $d$, defined as the diameter of a circle with the same area that surface area of the grain. The average equivalent diameter $E(d)$, and the coefficient of variation, $\mathrm{CV}(d)$, defined as the ratio of the standard deviation to the mean value, were determined. The shape of the grains was determined using the elongation parameter, defined as the ratio of the maximum diameter to the equivalent diameter of given grain $d_{\text {max }} / d$.

The ribbons were also investigated via X-ray diffraction (XRD), using $\mathrm{CuK}_{\alpha}$ radiation, from the air side, as it is a standard technique for their indirect characterization.

\section{Results and discussion}

\section{Microscopic observations}

Microscopic observations were carried out using FIB system to examine the structure of as-received ribbons on the wheel and air side. Based on such observations it has been found that these two sides of the melt-spun ribbons differ in their microstructures (Fig. 1). On the air side, regular grains with well-defined grain boundaries are visible for both the alloys investigated here. Different contrast of grains is related to their various crystallographic orientations. The size and shape of these grains change with the alloy composition. In the case of $\mathrm{Al}_{90.5} \mathrm{Si}_{9} \mathrm{Zr}_{0.5}$, the average equivalent diameter of the grains is $270 \mathrm{~nm}$ whereas for $\mathrm{Al}_{84.5} \mathrm{Si}_{15} \mathrm{Zr}_{0.5}$ it equals to $190 \mathrm{~nm}$ (Table 1). It should be noted that the distribution functions of the size of individual grains are relatively wide, as indicated by the coefficient of variation reaching the value of 0.5 . The average elongation factor close to 1.5 indicates slight elongation of grains.

On the wheel side, the structure features grains of similar geometry, however, with 'diffused grain boundaries' (they look thick with dark contrast). As a result, the structure might be considered two-phased one, with second phase forming the grain boundaries. It should be noted that the fraction of 'grain boundary phase' is much higher in the case of $\mathrm{Al}_{84.5} \mathrm{Si}_{15} \mathrm{Zr}_{0.5}$ alloy. The dark contrast, visible especially in Fig. 1d is related to small size of different oriented crystallites.

The non-homogeneity of the microstructure across the ribbons thickness are also clearly seen in TEM images obtained for the samples cut with FIB, as shown in Fig. 2. The microstructure close to the wheel side consists of equiaxial grains with 'diffused grain boundaries' (Fig. 2a (bottom), c). The measured size of $\mathrm{Al}$ grain is around $300 \mathrm{~nm}$ for both alloys and well corresponds to that estimated from FIB images. This indicates that the grains on the wheel side have regular shape in three dimensions. The wheel side zone of equi-axial grains is limited to about $20 \mu \mathrm{m}$ in thickness.

In contrast to the geometry of grains at the wheel side, in the areas close to the air side, elongated columnar aluminium grains, perpendicular to the surface are observed (Fig. 2a (top), b). These elongated grains have few hundreds of nanometer in width which well corresponds to the size of grains observed in FIB on the air side of the ribbon. The length of columnar grains is up to $10 \mu \mathrm{m}$.

A selected area electron diffraction (SAED) pattern taken from the area of $3 \mu \mathrm{m}$ in diameter, close to the air side of rapidly solidified $\mathrm{Al}_{84.5} \mathrm{Si}_{15} \mathrm{Zr}_{0.5}$, is given as an inset in Fig. 2b. The figure shows spots of $\mathrm{Al}$ phase and rings of silicon phase. Such a diffraction pattern indicates relatively coarse aluminium grains and nanocrystalline silicon phase.

Element mapping by energy-dispersive X-ray spectrometry (EDS) from the area close to the wheel side have shown that grain boundaries feature higher silicon content (Fig. 3). Grain interiors are rich in aluminium with homogenous distribution of $\mathrm{Si}$. It should also be noted that 
Fig. 1 FIB secondary electron images taken at $\mathbf{a}$ air side of $\mathrm{Al}_{90.5} \mathrm{Si}_{9} \mathrm{Zr}_{0.5}$, b air side of $\mathrm{Al}_{84.5} \mathrm{Si}_{15} \mathrm{Zr}_{0.5}$, $\mathbf{c}$ wheel side of $\mathrm{Al}_{90.5} \mathrm{Si}_{9} \mathrm{Zr}_{0.5}$, and $\mathbf{d}$ wheel side of $\mathrm{Al}_{84.5} \mathrm{Si}_{15} \mathrm{Zr}_{0.5}$

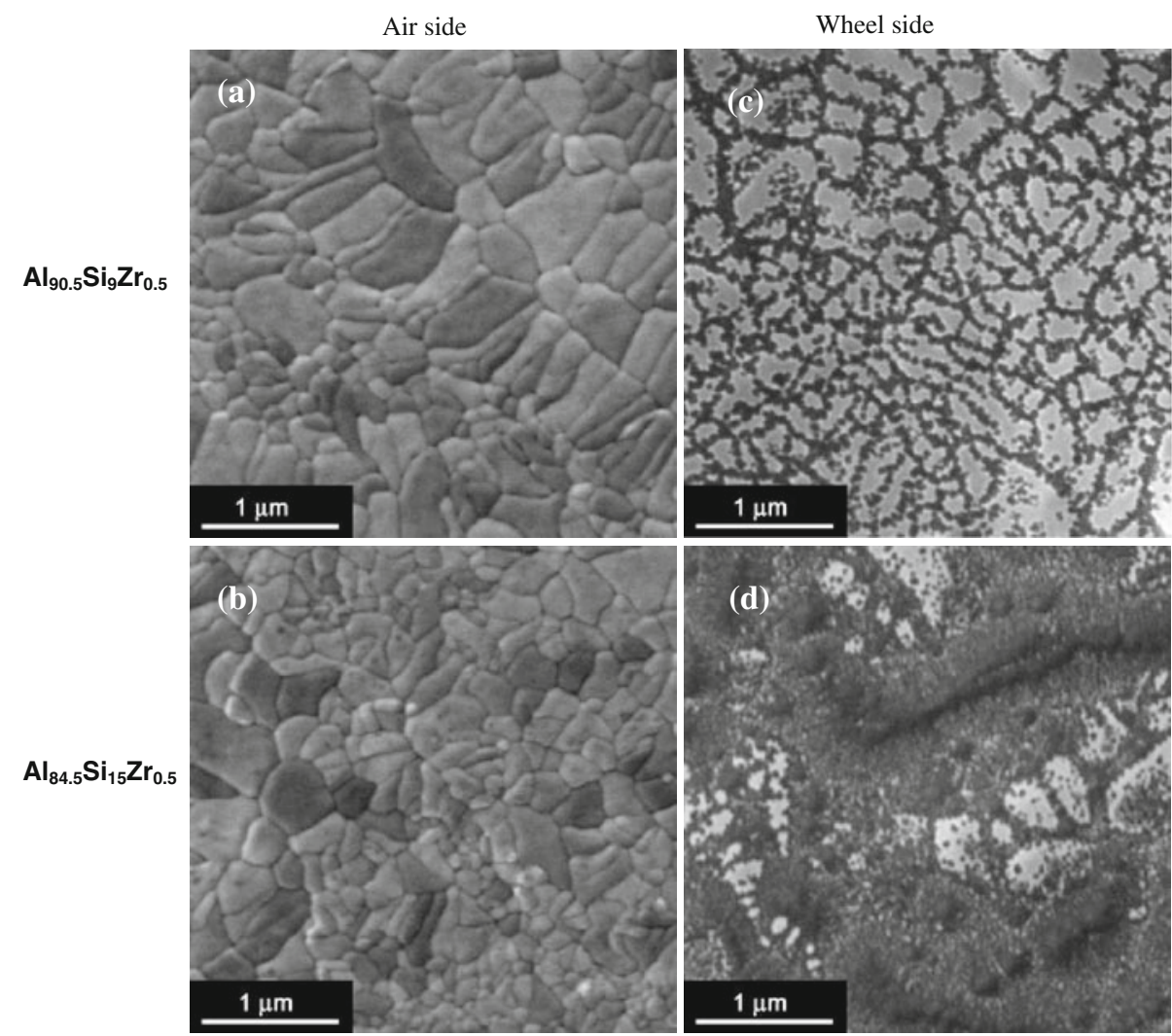

Table 1 Microstructural parameters determined from FIB images for $\mathrm{Al}_{84.5} \mathrm{Si}_{15} \mathrm{Zr}_{0.5}$ and $\mathrm{Al}_{90.5} \mathrm{Si}_{9} \mathrm{Zr}_{0.5}$ alloys

\begin{tabular}{llll}
\hline Alloy & $E(d)(\mathrm{nm})$ & $\mathrm{CV}(d)$ & $d_{\max } / d$ \\
\hline $\mathrm{Al}_{90.5} \mathrm{Si}_{9} \mathrm{Zr}_{0.5}$ air side & 273 & 0.47 & 1.53 \\
$\mathrm{Al}_{84,5} \mathrm{Si}_{15} \mathrm{Zr}_{0,5}$ air side & 189 & 0.43 & 1.45 \\
\hline
\end{tabular}

analysed signal for zirconium is very weak, so we can not definitely say that distribution of zirconium is homogeneous.

More detailed investigations, at higher magnifications, revealed that the 'grain boundary phase' on the wheel side consists of homogenously distributed Si-rich nanoprecipitates embedded in $\mathrm{Al}$ matrix (Fig. 4). Their diameter does not exceed $50 \mathrm{~nm}$. No precipitates have been observed inside equi-axial grains. Such a structure (aluminium primary grains with eutectic consisting of Si nano-precipitates embedded in $\mathrm{Al}$ matrix) revealed for both alloys is typical for hypoeutectic solidification although $\mathrm{Al}_{84.5} \mathrm{Si}_{15} \mathrm{Zr}_{0.5}$ alloy has hypereutectic composition and during traditional casting solidifies as hypereutectic. The difference comparing to conventional casting is the size of Si precipitates (few microns for conventional and nanometric for RS).

A HR-STEM image of a Si nano-precipitate with [110] zone axis is presented in Fig. 5. The image reveals multitwin structure of the precipitates, typical for $\mathrm{RS}$ of $\mathrm{Al}-\mathrm{Si}$ alloys [10].
Nanosized precipitates are also observed on the air side (Fig. 6). However, at this side, they are located not only at grain boundaries but also homogenously spaced inside columnar grains. The size of precipitates in this case is similar to the size of Si nanoprecipitates on the wheel side of the ribbons and does not exceed $50 \mathrm{~nm}$.

Observations under higher magnification (Fig. 6b, c) indicate that nano-precipitates on air side differ in their chemical composition. It is clearly visible in the HAADFSTEM image (Fig. 6c) where the contrast is related to chemical composition-brighter regions contain heavier elements. Precipitates located at the boundaries of columnar grains are brighter that suggests higher concentration of Si. It should be noted that the precipitates at grain boundaries are larger than those inside grains. Observations in BF-STEM mode (Fig. 6b) revealed fine areas with darker contrast, which are weakly visible in HAADF-STEM mode. It might indicate that these areas are $\mathrm{Al}$ nanocrystals embedded in supersaturated aluminium matrix. Similar precipitates of fcc $\alpha$-Al were observed in rapidly solidified $\mathrm{Al}-\mathrm{Si}-\mathrm{Cu}-\mathrm{Mg}$ alloys [11].

\section{XRD}

Figure 7 shows XRD patterns obtained for the as-meltspun $\mathrm{Al}_{90.5} \mathrm{Si}_{9} \mathrm{Zr}_{0.5}$ and $\mathrm{Al}_{84.5} \mathrm{Si}_{15} \mathrm{Zr}_{0.5}$ ribbons, obtained for the wheel side. One can notice sharp crystalline peaks of 

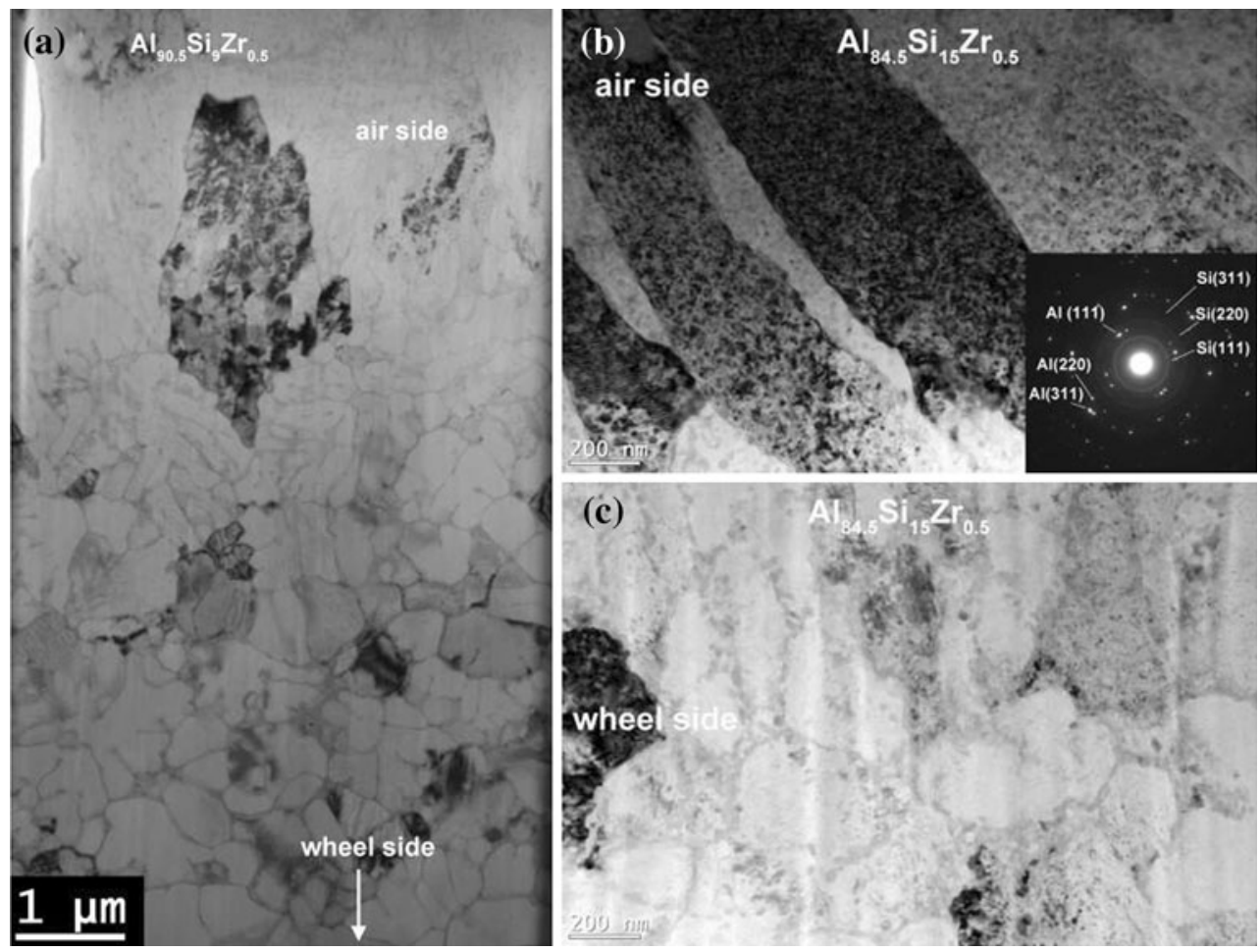

Fig. 2 Microstructures observed in thin foils cut perpendicular to the surface of a $\mathrm{Al}_{90.5} \mathrm{Si}_{9} \mathrm{Zr}_{0.5}$ alloy ribbon, $\mathbf{b} \mathrm{Al}_{84.5} \mathrm{Si}_{15} \mathrm{Zr}_{0.5}$ alloy ribbon-air side, and $\mathbf{c} \mathrm{Al}_{84.5} \mathrm{Si}_{15} \mathrm{Zr}_{0.5}$ alloy ribbon-wheel side

Fig. 3 EDS mapping of

elements in $\mathrm{Al}_{90.5} \mathrm{Si}_{9} \mathrm{Zr}_{0.5}$ alloy

ribbon (wheel side)
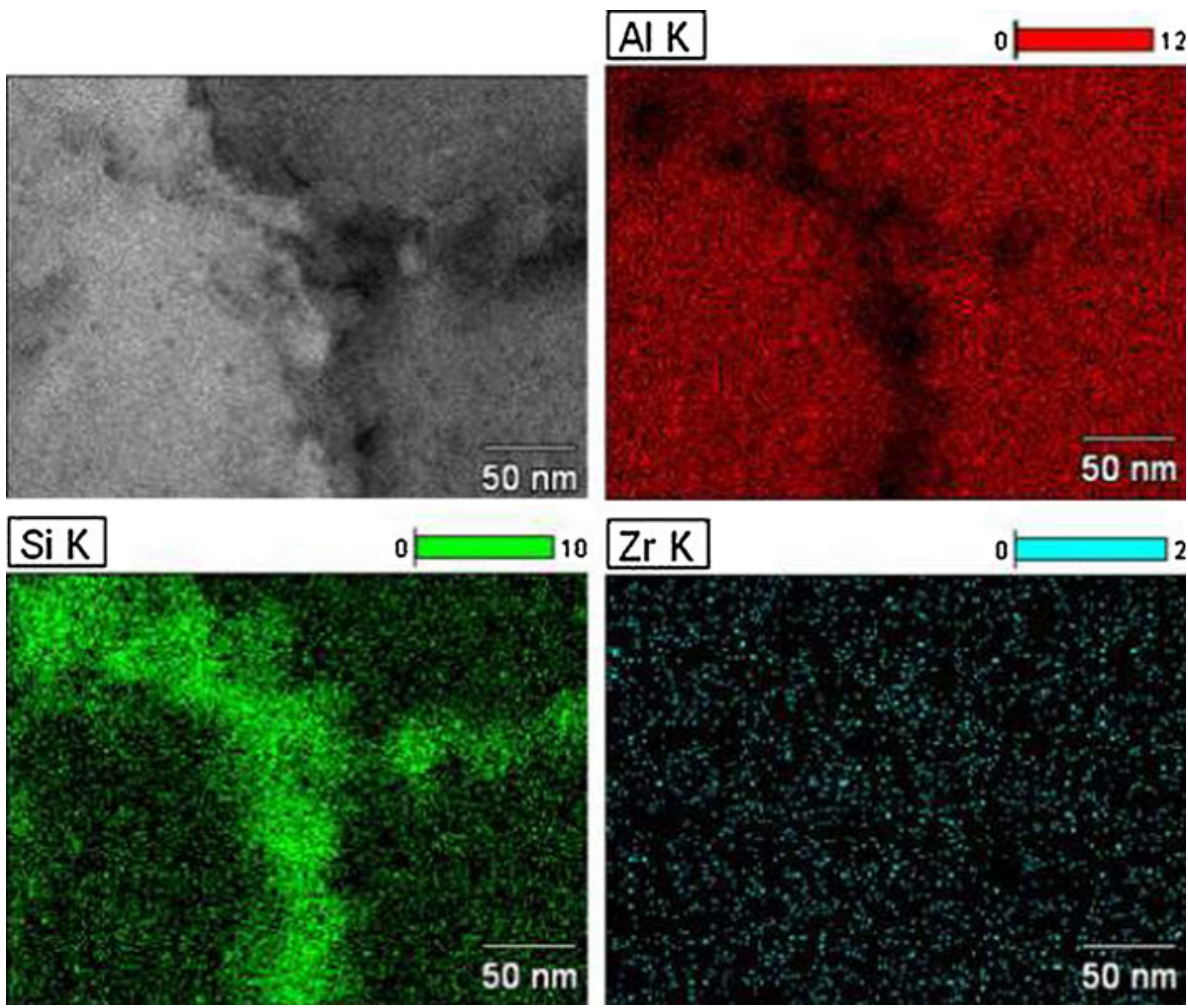
Fig. 4 Microstructure of $\mathrm{Al}_{90.5} \mathrm{Si}_{9} \mathrm{Zr}_{0.5}$ ribbon (wheel side) imaged in BF-STEM
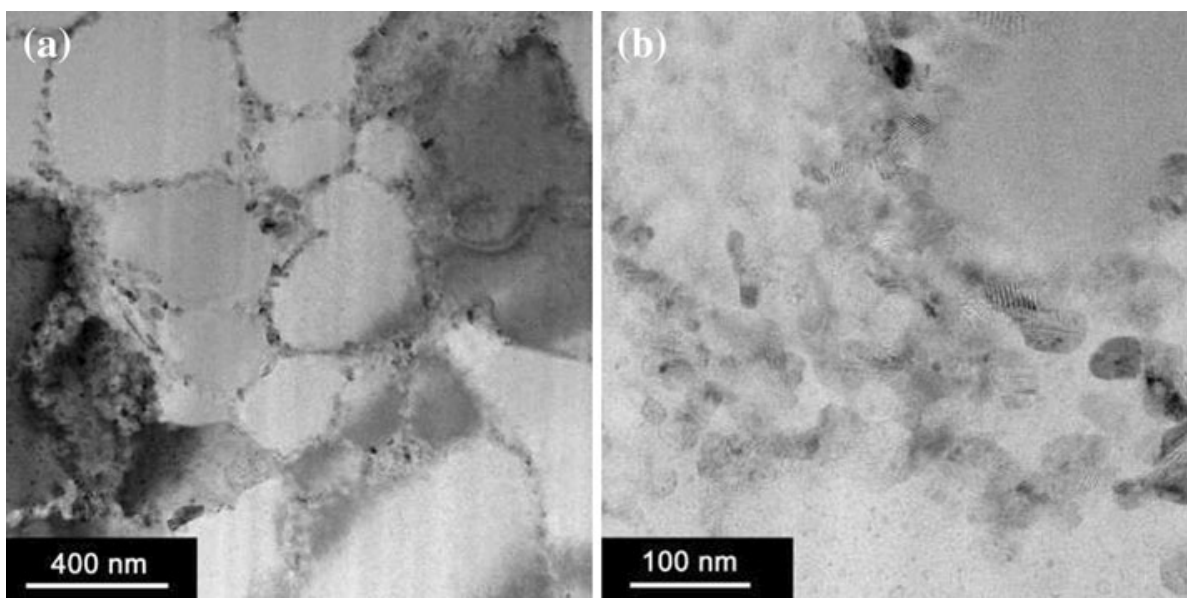

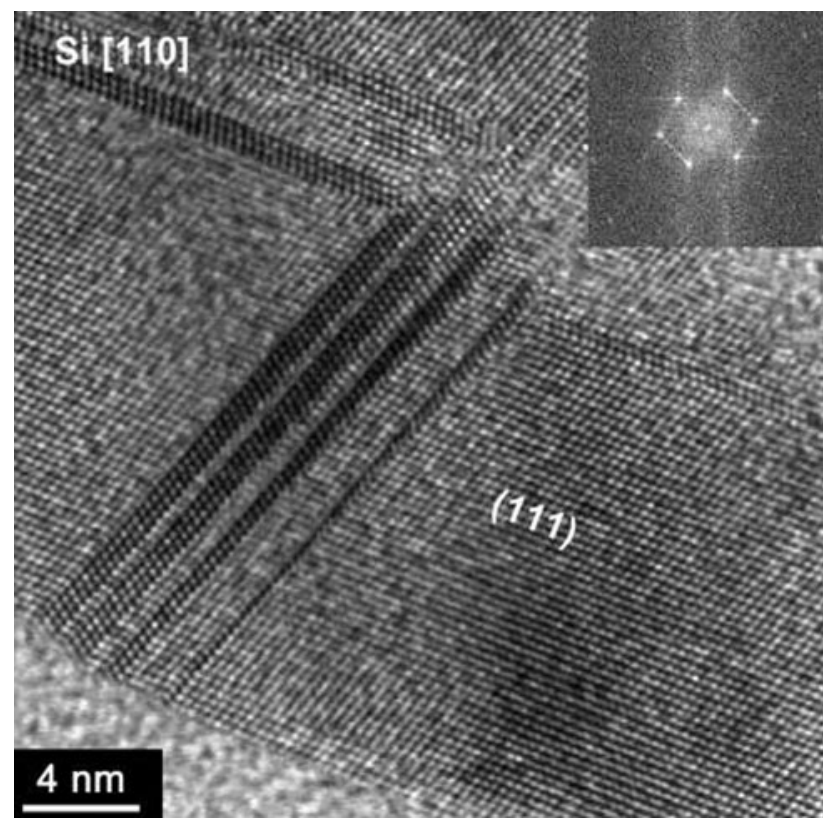

Fig. 5 High resolution BF-STEM image of Si crystal obtained by RS of $\mathrm{Al}_{84.5} \mathrm{Si}_{15} \mathrm{Zr}_{0.5}$ alloys the $\alpha$-Al phase on the both patterns. Weak and broad Si peaks indicating on existence of silicon phase also. The results suggest that most of the added $\mathrm{Si}$ and $\mathrm{Zr}$ are dissolved in $\alpha$-Al phase. The absence of broad 'diffuse' peak related to amorphous phase indicates completely crystalline structure of the produced ribbons.

The lattice parameters of $\alpha$-Al phase estimated from the XRD pattern for both alloy, $\left(\mathrm{Al}_{90.5} \mathrm{Si}_{9} \mathrm{Zr}_{0.5}-0.40357 \mathrm{~nm}\right.$, $\mathrm{Al}_{84.5} \mathrm{Si}_{15} \mathrm{Zr}_{0.5}-0.40370 \mathrm{~nm}$ ) is smaller than that of pure aluminium $(0.40497 \mathrm{~nm})$. This suggests relatively high Si content in $\alpha$-Al phase, as the lattice parameter of $\alpha-\mathrm{Al}$ decreases linearly with increasing silicon content in solid solution [12]. The difference of lattice parameter in two alloys is negligible.

\section{Conclusions}

High resolution, multi-technique characterization of the rapidly solidified ribbons of $\mathrm{Al}-\mathrm{Si}-\mathrm{Zr}$ alloys has revealed their complex nano- and micro-structure with clearly (a)

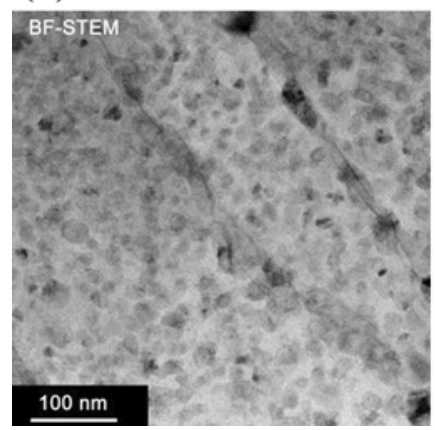

(b)

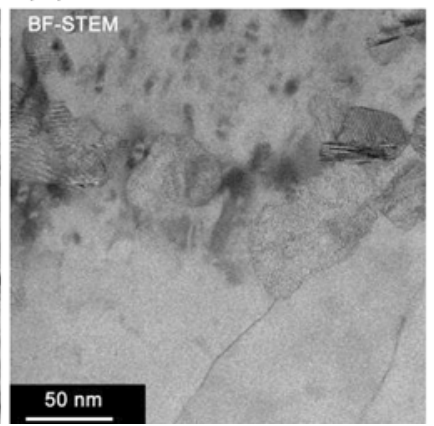

(c)

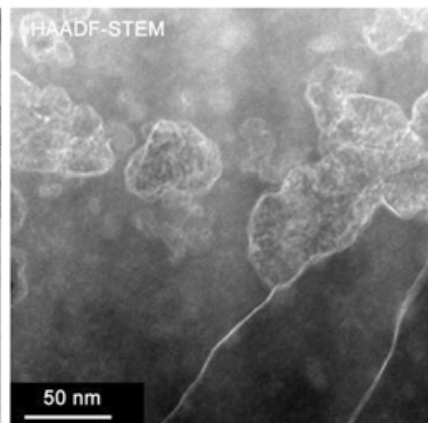

Fig. 6 Microstructure of $\mathrm{Al}_{84.5} \mathrm{Si}_{15} \mathrm{Zr}_{0.5}$ alloys ribbon (air side) imaged in a, b BF-STEM and $\mathbf{c}$ HAADF-STEM 


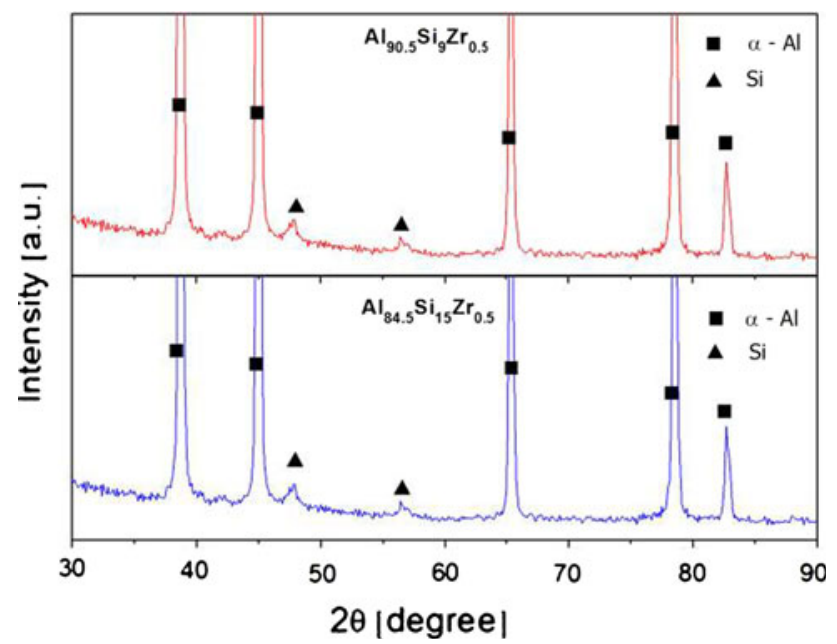

Fig. 7 XRD pattern of as-melt-spun $\mathrm{Al}_{90.5} \mathrm{Si}_{9} \mathrm{Zr}_{0.5}$ and $\mathrm{Al}_{84.5} \mathrm{Si}_{15} \mathrm{Zr}_{0.5}$ ribbons

defined wheel and air sub-layers. The wheel sub-layer features equiaxial Al grains $300 \mathrm{~nm}$ in diameter with $\mathrm{Si}$ nanoparticles embedded in Al matrix in grain boundaries (inter-grain phase). The air side sub-layer reveals columnar Al grains with nanoparticles homogenously distributed in the grain interiors. It should be noted that only minor differences in the structure of the ribbons were observed, despite the fact that the investigated alloys had hypo- and hyper-eutectic chemical compositions.

The results reported here give a new insight into nanostructure of RS Al-Si alloys which are routinely studied via observations on in-plane thin foils providing simplified image of the true structure. Similarly, XRD studies do not account for the complexity of the structure of such materials. The new comprehensive description presented here can be also used to characterize the structure of RS alloys with other chemical compositions which are often considered as homogenous through the thickness.

Acknowledgements This study was carried out within a NANOMET project financed under the European Funds for Regional Development (Contract No. POIG.01.03.01-00-015/08).

Open Access This article is distributed under the terms of the Creative Commons Attribution Noncommercial License which permits any noncommercial use, distribution, and reproduction in any medium, provided the original author(s) and source are credited.

\section{References}

1. Gaidarova V (2007) Vacuum $81: 1082$

2. Uzun O, Karaaslan T, Gogebakan M, Keskin M (2004) J Alloys Compd 376:149

3. Latuch J, Kulik T, Dimitrov H (2004) Mater Sci Eng A 375-377:956

4. Uzun O, Karaaslan T, Keskin M (2001) Turk J Phys 25:455

5. Lavernia EJ, Ayers JD, Srivatsan TS (1992) Int Mater Rev 37:1

6. Latuch J, Cieślak G, Kulik T (2007) J Alloys Compd 434-435:272

7. Sepehrband P, Mahmudi R, Khomamizadeh F (2005) Scr Mater $52: 253$

8. Srinivasana D, Chattopadhyay K (2001) Mater Sci Eng A 304-306:534

9. Stoichev N, Petrov K, Yaneva S, Kovachev P, Tzvetanova N (2002) Mater Sci Eng A 337:12

10. Kima T-S, Lee B-T, Lee CR, Chun B-S (2001) Mater Sci Eng A 304-306:617

11. Alfonso I, Maldonado C, Gonzalez G, Medina A, Bejar L (2006) AZojomo J Mater Online 2

12. Bendijk A, Delhez R, Katgerman L, de Keijser ThH, Mittemeijer EJ, van der Pers NM (1980) J Mater Sci 15:2803. doi:10. 1007/BF00550549 